Received: June 23, 2017 Accepted: July 10, 2017 Published: July 25, 2017

\section{Pregnancy, Exercise and Late Effects in the Offspring until Adult Age}

\author{
Jana Pařízková*
}

\begin{abstract}
Obesity Management Centre, Institute of Endocrinology, Prague, Czech Republic
*Corresponding author: Dr. Jana Pařízková, Obesity Management Centre, Institute of Endocrinology, Prague, Czech Republic,Tel:+420224905104;Fax:+420224905325;E-mail: jparizkova@endo.cz
\end{abstract}

\section{Abstract}

Maternal exercise during pregnancy as one of the critical periods can have significant delayed effect in the offsprring's fetal imprinting of future development until adult age; adequate and voluntary exercise is provided, not a forced one as a stress. Spontaneous physical activity of the offspring until adult age can be increased, and body composition, cardiac micro structure and reactibility (greater resistance to noxi), vasomotor function, glucose metabolism, insulin sensitivity along with related diseases (diabetes) can be positively influenced. Bone development and also the enhancement of brain function and learning sensitivity can be improved as revealed in a number of experimental model animal studies. Exercise during pregnancy was also shown to compensate in the offspring the detrimental effect of inadequate, e.g. high fat diets. Possibility of introducing significant modifications of the programming of the offspring's desirable development and health status by adequate and physiological maternal exercise during pregnancy was supported also by some observations in humans.

\section{Keywords}

Pregnancy; Exercise; Delayed Effects; Offspring; Adult Age; Physical Activity; Metabolic; Vascular; Brain Consequences

\section{Abbreviations}

PA - physical activity; Ex - exercise

\section{Introduction}

The level of physical activity (PA) and exercise (Ex) is an important environmental stimulus which has significant effect on a number of metabolic, humoral, functional, morphological, psychological and other characteristics of the organism which can manifest not only at present, but also as delayed consequences when implemented since the very beginning of life. Such effects depend on the character, intensity, frequency, duration of $\mathrm{PA}$ régimes and/or Ex, and the reaction and consequences can be also further modified by eventual adaptation to them when applied gradually and repeatedly during appropriate periods of time. Increased physical fitness, reduced adiposity along with reduced metabolic, musculoskeletal and psychological problems can result from adequate exercise, especially when applied during growth $[1,2]$. On the other hand, sudden forced implementation of increased Ex can become a stress with undesirable results as revealed e.g. in experimental models $[3,4,5]$.

Previous studies on the impact of Ex which modifies significantly energy balance and turnover showed also that the earlier such a stimulus is implemented and the longer it lasts, the more apparent are its manifestations; the adequacy of such a stimulus is essential, and should always have a character as related to the level of development of the organism when Ex is started to be implemented. Moreover, this effect can appear and has a special character when applied through the régime of PA of the pregnant mother [3-6].

Fetal origin hypothesis of morbidity [4, 5, 7, 8, 9] and metabolic imprinting by prenatal, perinatal and postnatal factors [6-10] concern also PA and Ex. Their impact can be transferred during pregnancy on the fetus due to physical activity régimes and reactive changes to them of the pregnant mother, and could manifest significantly in the offspring during its own postnatal period up to the adult age. The effect of PA is closely interrelated with the impact of nutrition manifesting energy balance and turnover, and the effects of these relationships can be mediated 
and reflected also as delayed effects later in life. Changed nutrition of both, restricted and high fat diet during gestation can alter, along with low birth weight also physical activity [11].

Most important of the effects of adequate PA and Ex régimes during pregnancy are those which have more permanent character due to the intervention in the programming of the fetus under physiological conditions, in a way which can be considered positive for the development of health and overall fitness during later life up to adulthood. This has been supported by empirical and some practical observations, and has been studied both in humans and experimental models. Evidence-based prenatal exercise guidelines have been recommended to counsel healthy and adequately functionally well disposed pregnant women for appropriate and safe physical activity régimes [12].

\section{Interrelationships between early nutrition related to physical activity}

Most long-term data exist on the effect of maternal nutrition - energy intake related to its expenditure during pregnancy. Exposure to famine in utero and in early infancy during and shortly after WW2 resulted in more frequent obesity in young Dutch men; however, PA and energy expenditure later in life were not followed up [13]. Mother's undernutrition during pregnancy resulted in long-term shift of their offspring's nutrition and physical activity choices, i.e. preference for wheel running versus lever pressing for food [14]. Inequalities in nutrition - food restriction and/ or high-fat diet during gestation induced reduced birth weight, and altered also the level of PA in adult offspring [11].

Developmental programmings of metabolic disorders in the offspring of obese mothers were discussed, with regard to the elucidation of mechanisms underlying altered obesity risk in the offspring [15]. Intrauterine origin of adult morbidity due to fetal programming was considered to be influenced by various changes of internal milieu of the mother, e.g. modification of its acidity which change the frequency of heart rate of the fetus and its movements in the womb [16].

Fetal growth restriction due to reduced food intake reduced physical activity and energy expenditure, and increased obesity in female, not male offspring mice [17]. Diet with decreased percent of protein fed to rat mothers during weaning decreased in the offspring slightly body weight and fatness along with increased economy of following growth (expressed as $\mathrm{g}$ diet / $\mathrm{g}$ body weight increase), increased spontaneous PA level in running wheels and reduced experimental cardiac necrosis and mortality after isoprenaline application in adult age $[6,18,19]$. Early interventions including fetal one concerning energy balance and turnover has appeared to be significant for adult health and sensitivity to noxi.

\section{Effect of exercise during pregnancy in humans}

PA during pregnancy has been considered especially from the point of view of the influence on health risks of the mother and offspring. Observations in the mother and the outcome of pregnancy revealed mostly beneficial effects of an adequate PA régimes during pregnancy, depending on their character and in- tensity. Significant changes of birth weight gain and subcutaneous fat distribution due to PA appeared during second half of pregnancy [21]. Pregnant women who continued in endurance Ex gave birth to children with significantly lower birth weight, lower ponderal indexes, smaller fetoplacental weight ratios and lower skinfold thicknesses ; crown-heel lengths and head circumferences were not influenced [22,23]. Interruption or reduction in preconceptional Ex increased birth weight and skinfolds of newborns [23]. However, consequence of PA interventions during pregnancy in later life were not reported, or only those manifested e.g. at the age of 18- 24 months only [24].

The adequacy of Ex during normal pregnancy has to be carefully specified and defined; moderate regular Ex does not have an adverse effect on the neurodevelopment of the child and motor skills up to 18 months of age [25]. Aerobic Ex training has been determined as safe and efficacious throughout pregnancy, but other characters of physical training (circuit and resistance) have been studied only more recently [26]. The effect of Ex during pregnancy of women spending at least 20 min three times per week, at minimum intensity of $55 \%$ of their maximal aerobic capacity on newborn's brain was considered to give insight on fetal neuroplasticity [27].

The amount, range and type of PA which was performed before becoming pregnant were followed in Polish women; in addition, comparisons were made between the infant and newborn status using the APGAR scale with the amount of PA performed by the mother. There were decidedly low PA levels observed in pregnant women compared to those before becoming pregnant. Interventions have to be targeted to test the hypothesis and attempt to identify the most appropriate levels for intensity, duration and frequency of PA and Ex during pregnancy which are considered to have also a direct relationship on the method of delivery and health of the newborn [28].

Most studies on the effect of PA and Ex during fetal period concern those manifested in the offspring after birth, or in very young subjects), but fewer also for those in later life up to the adult age. However, a study in the offspring of mothers who remained physically active during pregnancy displayed more positive academic performance at the age of 6-18 years [29] revealing benefits of the continuing maternal PA practice (however, the contribution of additional possible factors were not analyzed). Higher birth weight, smoking status and low physical activity during pregnancy were also associated with obesity in the offspring at the age of 8 years [30].

In humans it has been hardly possible to follow up separately, without interference of other factors, the effect of PA and Ex during normal pregnancy, in the offspring later in life. Studies of the long-term influence of PA and Ex during pregnancy have been therefore mostly conducted in experimental models with animals, mostly laboratory.

\section{Late effects of PA and Ex during pregnancy in experimental animal models}

Offspring of mice mothers which had access to spontaneous PA in running wheels during pregnancy displayed lifelong propensity for higher PA as compared to offspring of inactive mothers, 
along with slightly higher weight at birth. Body weight and composition later in life when they had no possibility to use running cages no differences were found [31]. However, in other comparably arranged experiments the differences between the offspring of mice using running wheels or inactive ones during pregnancy were not found; the same concerned body composition. At the level of the individual, correlation analyses revealed some statistically significant relationships between maternal and offspring Ex levels, likely reflecting previously known heritability estimates for such similar PA [32].

Gestational exercise of swine mothers was revealed as a potent stimulus for programming vascular smooth muscle relaxation in adult offspring. Ex training for the finite duration of mother decreased in adult offspring vascular smooth muscle responsiveness to an exogenous nitric oxide donor, i.e. vasomotor function of adult offspring can be thus programmed by mother's exercise during pregnancy [33]. However, other experiments using Sprague Dawley rats showed that maternal wheel running during pregnancy did not significantly modify behavior or vascular function in adult offspring, i.e.vasorelaxation response to acetylcholin or sodium nitroprusside [34]. Significant effect of maternal Ex (1 hour of daily running on a running carpet at the speed $20 \mathrm{~m} / \mathrm{min}$.) was found in Sprague Dawley rats during the whole period of pregnancy. Number of fibers and capillaries, capillary/fibre ratio were increased, and diffusion distance reduced in the heart, i.e. these parameters of the heart development were significantly changed in the offspring of exercised rats at the age of 110 days, positively with regard to function. This prenatal impact was further positively increased by similar Ex during postnatal life in other groups up to 110 days; the character of changes indicated that Ex impact during pregnancy was more important $[6,35,36]$. This effect on heart microstructure was confirmed along with aerobic power [35]. Negative effect of isoprenaline application on the development of experimental cardiac necrosis and mortality in adult offspring of rat mothers exercised during pregnancy was significantly less harmful as compared to the offspring of control mothers [37].

The effect of strenuous Ex at the level of 70, 80, 90 percent of VO2 max was followed in the offspring of rat mothers exercised during pregnancy: weight of heart, capillary/fibre ratio in newborn rats and their VO2 max at the age of 90 days were assessed. The body weight was reduced - was less in mostly Ex offspring, capillary/fibre ratio was different compared to control inactive group. The effect of Ex was shown to depend of the relative work load applied to the mother, which was particularly marked at high work loads [38].

Moderate Ex during pregnancy can change also musculoskeletal system and body composition in the offspring, i.e. Alter bone and adiposity in a gender-specific way [39]. The positive effects of preconceptual training comparing groups of female mice with or without voluntary Ex in running wheels were revealed in significant changes of bone gene expressions, in particular to- wards osteogenic remodelling markers [40].

\section{Metabolic consequences of exercise during pregnancy in the offspring}

Glucose metabolism in skeletal muscle and fat of weanling rats was significantly influenced by modest voluntary Ex (running wheels) of mothers during pregnancy; maternal exercise appeared to decrease the metabolic risk induced by maternal obesity improving insulin/glucose metabolism, with more apparent effect in male than female offspring [41].

Preliminary evidence on the effect of voluntary Ex during pregnancy was found in the offspring compared with offspring of sedentary mice at the age of 8 weeks, when following at similar age of two generations. Small, but broad generation- and sexspecific effects of Ex ancestry were observed for body mass, fat and muscle mass, serum insulin, glucose tolerance and muscle gene expression (mRNA levels for multiple genes, especially those related to metabolic genes), which varied with regard to first and second generation of mice followed up [42].

Long-term glucose homeostasis in the offspring of mothers Ex during pregnancy was shown to be also influenced. Blood glucose concentrations were reduced to lower values in response to an intraperitoneal insulin tolerance test for both male and female adult offspring of parents with access to running wheels. Male offspring from exercised mice showed increased percent of lean body mass along with decreased fat mass percent compared with male offspring from sedentary dams; in females no differences were found [43].

The comparison of the offspring of Ex and sedentary Sprague-Dawley rat mothers showed that intrauterine environment can influence insulin sensitivity in mature age. Adult female offspring born to Ex mothers had enhanced glucose disposal during glucose tolerance testing as well as increased glucose infusion rates and whole body glucose turnover rates during hyperinsulinemic - euglycemic clamp testing compared with offspring from sedentary dams. Offspring of exercised dams had also, compared to offspring of sedentary dams, decreased insulin levels and hepatic glucose production during the clamp procedure, and increased glucose uptake in skeletal muscle, along with decreased heart glucose uptake in response to insulin infusion during the clamp procedure. Apparently Ex during pregnancy enhances offspring's insulin sensitivity and improves glucose homeostasis, which can decrease offspring susceptibility to insulin-resistant related diseases such as type-2 diabetes mellitus [44].

With regard to metabolic health, the effect of Ex before and during pregnancy can compensate positively e.g. the effect of inadequate diet fed to male offspring of mothers with different PA. Ex (swimming) of mothers during pregnancy prevents negative effect of high fat diet inducing obesity in adult mouse; this could be important for succeeding generations as well [45].

Offspring of chow-fed diet dams who trained in running wheels before and during gestation had improved glucose tolerance beginning at 8 weeks of age and continuing throughout the 1st year of life, and at 52 weeks of age had significantly lower serum insulin concentrations and percent body fat compared to other groups (sedentary with different diets). High-fat feeding of 
sedentary dams resulted in impaired glucose tolerance, increased serum insulin concentrations, and increased percent body fat in the offspring. Apparently, maternal Ex before and during gestation compensated and ameliorated the detrimental effect of a maternal high fat diet on the metabolic profile of the offspring [46]. Central leptin sensitivity and signalling in adult offspring of dams fed high-fat diet during pregnancy and lactation can be improved by Ex also during early weaning period, through the effects on hypothalamic neuropeptide and receptor mRNA expression [47].

\section{Exercise effects on brain function of the offspring}

Maternal running during pregnancy has also been suggested to exert beneficial effects on brain functions of the offspring. Experiments in the offspring of rats exercised during pregnancy revealed significant increase in the expression of leptin receptor in prepubertal male rat offspring (not in prepubertal female pups), enhanced hippocampal cell survival and improved learning memory capability in prepubertal and adult male pups, as compared to control group without pregnant mother's Ex. These results showed that maternal Ex during pregnancy may regulate spacial plasticity in the hippocampus of the offspring by increasing the expression of leptin secreted from adipose tissue, which has positive effects on learning, memory and synaptic plasticity [48].

Ex of pregnant rat mother enhanced also cognitive functions (habituation behavior and spatial learning) in the offspring, and increased brain-derived neurotrophic factor levels and cell numbers in the hippocampal formation of the offspring [49]. Maternal swimming during pregnancy increased mitochondrial mass and membrane potential suggesting mitochondrogenesis in cerebellum and parietal cortex of pups, i.e. neurometabolic programming in the offspring by Ex during fetal period [50]. However, forced maternal Ex at high intensity had a negative effect on the neurogenic niche development in postnatal offspring - reduction of cell proliferation in the postnatal dentate gyrus of mouse offspring [3]. Testing of object recognition memory and following the increase c-FOS- positive cells expression in peripheral cortex, suggested that ex during pregnancy may enhance also brain function of the male offspring of exercised mothers $(\sim 0.76 \pm 0.09$ $\mathrm{km})$ per night in the running wheel [51].

\section{Conclusions}

Selected long-term studies of the effect maternal Ex during pregnancy on their offspring later in their life revealed significant changes of a number of characteristics, starting with the level of spontaneous PA. These follow-ups have not given always identical results, depending on Ex character : spontaneous, voluntary in running wheels and/or induced on running carpet, swimming etc., then, also intensity and duration of mother's Ex, species of experimental animals, character of delayed changes, age of the offspring when consequences were assessed, including total duration of experiments, etc. was not always identical and comparable. Effect of Ex in females of many species was complicated with regard to the changes of PA during estruous cycle, so results were not always apparent, or only males were used for experiments. Delayed consequences concerning level of spontaneous PA, morphological, metabolic and functional characteristics, brain function and morphology were found in the offspring prevailingly positive. When Ex has been adequately implemented, resulting changes appear to be desirable, indicating important physiological effect of maternal Ex during pregnancy on later functional development of their offspring's organism, its fitness and health prognosis until adult age.

\section{References}

1. Pař́źzová J: Body fat and physical fitness. Body composition and lipid metabolism in different regimes of physical activity. The Hague ; Martinus Nijhoff B.V. / Medical Division: 1977.

2. Pařízková J; Physical activity, fitness, nutrition and obesity during growth. In: Bentham E book. 5, $6^{\text {th }} \mathrm{Ch}$. EISBN 978-1-60805-946-1, ISBN.978 -1-60805-947-8, 150-295. Doi: 10.2174/97816080594611140101

3. Wasinski F, Estal GR, Arakaki AM, Bader M, Alenina N, Klempin F,et al. Maternal forced swimming reduces cell proliferation in the postnatal dentate gyrus of mouse offspring. Front Neurosci. 2016;10:402. Doi: 10.3389/fnins.2016.00402

4. Basta-Kaim A, Szczesny E, Glombik K, Stachowicz K, Slusarczyk J, Nalepa I,et al. Prenatal stress affect insulin-like growth factor 1-(IGF-1) level and IGF-1 receptor phosphorylation in the brain of adult rats. Eur. Neuropsychopharmacol. 2014;24(9);1546-1556.Doi: 10.1016/j.euroneuro.2014.07.002

5. Modir P, Elahdadi Salmani M, Goudarczi I, Lashkarboluki T, Abrari K. Prenatal stress decreases special learning and memory retrieval of the adult male offspring of rats. Physiol Behav. 2014;129:104-109. Doi: 10.1016/j.physbeh.2014.02.040

6. Pařízková J.: Nutrition, physical activity, and health in early life. $2^{\text {nd }} \mathrm{ch}, 2^{\text {nd }}$ ed. New York- Boca Raton-London; CRC Press, Taylor and Francis Group: 2010.

7. Barker DJP: Mothers, babies and diseases later in life. London; BMJ Publishing Group :1994.

8. Barker DJ, Martyn CN, Osmond C, Hales CN, Fall CH. Growth in utero and serum cholesterol concentrations in adult life. BMJ. 1993;307(6918):1524-1527.

9. Sultan HY. Programming a baby. In: Barker DJP: Mothers, babies and diseases later in life. BMJ Publishing Group 1994;14-36. 10. Dyer JS, Rosenfeld CR. Metabolic imprinting by prenatal, perinatal and postnatal over nutrition: a review.Semin Reprod Med. 2011;29(3):266-276. Doi: 10.1055/s-0031-1275521

11. Cunha F. da Silva, Molle RD, Portella AK, Silva Benetti CD, Noschang C, Goldani MZ ,et al. Both food restriction and high-fat diet during gestation induce low birth weight and altered physical activity in adult rat offspring: the "Similarities in the Inequalities" model. PLoS One. 2015;10(3):e0118586. Doi: 10.1371/journal.pone.0118586.

12. Wolfe LA, Weissgerber TL: Clinical physiology of exercise in pregnancy: a literary review. J Obstetrics Gynecol 2003;25(6):473-483.

13. Ravelli GP, Stein ZA, Sesser MW. Obesity in young men after famine exposure in utero and early infancy. N Engl J Med. 1976:295(7);349-353. Doi: 10.1056/NEJM197608122950701 
14. Miles JL, Landon J, Davison M, Krägeloh CU, Thompson NM, Triggs CM, et al. Prenatally undernourished rats show increased preferencies for wheel running v. lever pressing for food in a choice task. Br.J. Nutr. 2009;101(6):902-908. Doi: 10.1017/S0007114508043353.

15. Li M, Sloboda DM, Vickers MA. Maternal obesity and developmental programming of metabolic disorders in offspring: evidence from animal models. Exp.Diabetes Res. 2011:2011:592408. Doi:10.1155//2011/592408

16. Arshavski I. A: To the analysis of mechanisms contributing to the tempo of antenatal development of mammals and their significance for the determination of the dimensions of newborns and of the degree of their physiological maturity In: Tempo of individual animals' development of and its changes during evolution. Ed. House "Nauka", Moscow. 1968;:76-190 (in Russian).

17. Baker MS, Li G, Kohorst JJ, Waterland RA. Fetal growth restriction promotes physical inactivity and obesity in female mice. Int J Obes. 2015;39(1):98-104.

18. Pařízková J, Petrásek R, Fraňková S. The impact of reduced energy and protein intake at the beginning of life on growth, spontaneous motor activity and lipid metabolism in male rats. Ind J Nutr Diet. 1979;16:412- 418.

19. Pařízková J J, Faltová E, Mráz M, Špátová M. Growth, food intake, motor activity and experimental cardiac necrosis in early malnourished male rats. Ann Nutr Metab. 1982;26(2):121- 128.

20. Pař́zková J. From an inactive and obese to a fit child: how long is the way? Adv.Nutr. 2011;2(2):177S-181S. Doi: 10:3946/an, 111.000349

21. Clapp JF, Little KD. Effect of recreational exercise on pregnancy weight gain and subcutaneous fat deposition. Med Sci Sports Exerc. 1995:27(2);170-177.

22. Clapp JF, Capeless EL. Neonatal morphometrics after endurance exercise during pregnancy. Am J Obstet Gynecol. 1990;163(6):1905-1911.

23. Clapp JF, Burciu KH, Schmidt S, Petry K, Lopez B. Continuing regular exercise during pregnancy: effect of exercise volume on fetoplacental growth. Am J Obstet Gynecol. 2002;186(1):142147.

24. Mattram K, Mudd LM, Rudey RA, Kelly SCJ. Leisure-time physical activity during pregnancy and offspring size at 18 to 24 months. J Phys ActHealth. 2011;8(5):655-662.

25. Hellenes OM, Vik T, Løhaugen GC, Salvesen KÅ, Stafne SN, Mørkved S,et al. Regular moderate exercise during pregnancy does not have an adverse effect on the neurodevelopment of the child. Acta Pediatr. 2015;104(3);285-291.

26. Moyer C, Livingston J, Fang X, May LE. Influence of exercise mode on pregnancy outcomes: enhanced by Mom project. BMC Pregnancy Childbirth. 2015;9:15:133. Doi: 10.1186/s 12884-015

27. LeMoyne EL, Curnier D, St.Jacques S, Ellemberg D. The effects of exercise during pregnancy on the newborn's brain: study protocol for a randomized control trial. Trials. 2012;13:68. Doi: 10.1186/1745-6215-13-68

28. Wojtyla A, Kapka-Skrzypczak L. Paprzycki P, Skrzypczak M, Bilinski P. Epidemiological studies in Poland on effect of physical activity of pregnant women on the health of offspring and future generations - adaptation of the hypothesis development origin of health and disease. Ann. Agric. Environ. Med. 2012;19(2):315326.

29. Esteban-Cornejo J, Martinez-Gomez D, Tejero-González $\mathrm{CM}$, et al. UP and DOWN Study Group. Maternal physical activity before and during prenatal period and the offpsring's academic performance in youth. The UP and DOWN Study. J.Matern.Fetal Neomat. Med. 2016;29(9):1414-1420. Doi: 10.3109/14767058.2015.1049525

30. Mourtakos SP, Tambalis KD, Panadiokatos DB, et al. Maternal lifestyle characteristics during pregnancy, and the risk of obesity in the offspring: a study of 5,125 children. BMC Pregnancy Childbirth. 2016;15:66-76. Doi: 10./s1186/s12884-015-0498-z

31. Eclarinal JD,Zhu S, Baker MS, Piyarathna DB, Coarfa C, Fiorotto ML, et al. Maternal exercise during pregnancy promotes physical activity in adult offspring. FASEB J. 2016;30(7):25412548. Doi: 10.1096/fj.201500018R

32. Kelly S A., Hua K, Wallace JN, Wells ES, Nehrenberg LD, Pomp D. Maternal exercise before and during pregnancy does not impact offspring exercise or body composition in mice. J Negat Result Biomed. 2015;14:13. Doi: 10.1186/s12952-015-0032-x

33. Bahls M, Sheldon RD, Taheripour P, Foust KB, Breslin ED, Clifford KA et al. Mother,s exrcise during pregnancy programmes vasomotor function in adult offspring. Exp. Physiol. 2014;99:205-219. Doi: 10.1113/expphysiol.2013.075978

34. Blaize AN, Breslin E, Donkin SS, Cabot R, Pearson KJ, Newcomer SC. Maternal exercise does not significantly alter adult rat offspring vascular function. Med. Sci. Sports Exerc. 2015;47(11):2340-2346. Doi: 10.1249/MSS.0000000000000665

35. Pařízková J. Impact of daily workload during pregnancy on the microstructure of the rat heart in male offspring. Eur.J.Physiol. 1975;34(4):323- 326

36. Pařízková J J. Cardiac microstructure in female and male offspring of exercised rat mothers. Acta Anat. 1979;105(4):382327.

37.Pařízková J. Physical activity: Human growth and development. 5th Ch, New York and London; Rarick G.L. ( Ed.) Academic Press, Inc: 1973.

38. Picarro IC, Barros Neto TL, De Teves DC, Silva AC, Denadai Ds, Russo AK, et al. Effect of exercise during pregnancy, graded as a percentage of aerobic capacity: maternal and fetal responses of the rat. Comp. Biochem. Physiol . A Comp Physiol. 1991;100 (4):795-799.

39. Rosa BV, Blair HT, Vickers MH, Dittmer KE, Cameron GK, et al. Moderate exercise during pregnancy in Wistar rats alters bone and body composition of the adult offspring in a sex-dependent way. PloS One. 2013;8(12):e82378. Doi: 10.1371/journal.pone.0082378

40. Gaeini AA, Shafiei Neek L, Choobineh S, Satarifard S, Sayahpour FA, Mousavi SN, et al. Preconception endurance training with voluntary exercise during pregnancy positively influences on remodelling markers in female offspring bone J Matern Fetal Neonatal Med. 2016;29(22):3634-3640. Doi: $10.3109 / 14767058.2016 .1140140$ 
41. Raipuna M, Bahan $\mathrm{H}$, Morris MJ. Effects of maternal diet and exercise during pregnancy on glucose metabolism in skeletal muscle and fat of weanling rats. PloS One. 2015;10(4) :eO120980.

42. Guth LM, Ludlow AT, Witkowski S, Lima LC, Xiao AT, Roth SM, et al. Sex-specific effects of exercise ancestry on metabolic, morphological, and gene expression phenotypes in multiple generations of mouse offspring. Exp. Physiol. 2013;98(10):1469-1484. Doi: 10.1113/expphysiol.2012.070300 43. Carter LG, Lewis KN, Wilkerson DC, Tobia CM, Ngo TSY, Shridas $\mathrm{P}$ et al. Perinatal exercise improves glucose homeostasis in adult offspring. Am J Physiol Endocrinol Metab. 2012;303(8):E1061-E10618. Doi: 10.1152/ajpendo.00213.2012 44. Carter LG, Qi NR, De Cabo R, Pearson KJ. Maternal exercise improves insulin sensitivity in mature rat offspring. Med Sci Sports Exerc. 2013;45(5);832-840. Doi: 10.1249/MSS.0b013e31827de953

45. Wasinski F, Pereira Bacurao RF, Rufino Estrela G, et al. Exercise during pregnancy protects adult mouse offspring from diet-induced obesity. Nutr Metab(Lond). 2015;12:56. Doi: $10.1186 / \mathrm{s} 12986-015-0052-\mathrm{z}$

46. Stanford KI, Lee MY, Getchell KM, So K, Hrishman MF, Goodyear LJ. Exercise befiore and during pregnancy prevents deleterioue effects of maternal high.fat feeding on metabolic health of male offspring. Diabetes. 2015;64(2):427-433. Doi: $10.2337 / \mathrm{db} 13-1848$
47. Sun B, LKiang NCh, Ewald ER, Yan J, Moran TH, Boersoma GJ, et al. Early postweaning exercise improves central leptin sensitivity in offspring of rat dams fed high-fat diet during pregnancy and lactation. Am J Physiol Regul Integr Comp Physiol. 2013;305(9):R1076-R1084. Doi: 10.1152/ajpregu.00566.2012.

48. Dayi A, Agilkaya S, Ozbal S,Cetin F, Aksu I, Uysal N, et al. Maternal aerobic exercise during pregnancy can increase spatial learning by affecting leptin expression on offspring's early and late period in life depending on gender. Scientific World Journal 2012;2012:429803. Doi: 10.1100/2012/429803

49. Gomez da Silva S, Almeida AA, Fernandez J, Lopim GM, Lent $\mathrm{R}$, Cabral RA, et al. Maternal exercise during pregnancy increases BDNF levels and cell numbers in the hippocampal formation, but not in cerebral cortex of adult rat offspring . PLOS One. 2016;11(1):e0147200. Doi : 10 1371/journal.pone0147200

50. Marcellino TB, Langoni A, Kudo KY, Stone V, Rech A, Matte $\mathrm{C}$, et al. Evidences that maternal swimming exercise improves antioxidant defence and induces mitochondrial biogenesis in the brain of youth Wistar rats. Neuroscience 2013;246:28-39. Doi: 10.1016/j.neuroscience

51. Robinson AM, Buccu DJ. Physical exercise during pregnancy improves object recognition memory in adult offspring. Neuroscience. 2014;256:53-60. Doi:1016/j.neuroscience 